\title{
BMJ Open Protocol to assess the efficacy of carnosine supplementation in mitigating the adverse cardiovascular responses to particulate matter (PM) exposure: the Nucleophilic Defense Against PM Toxicity (NEAT) trial
}

Timothy E. O'Toole (D) , ${ }^{1}$ Alok A. Amraotkar, ${ }^{1,2}$ Andrew P. DeFilippis, ${ }^{3}$ Shesh N. Rai, ${ }^{4}$ Rachel J. Keith, ${ }^{1}$ Shahid P. Baba, ${ }^{1}$ Pawel Lorkiewicz, ${ }^{1,5}$ Catherine E. Crandell, ${ }^{6}$ Gina L. Pariser, ${ }^{6}$ Christopher J. Wingard, ${ }^{6}$ C. Arden Pope III, ${ }^{7}$ Aruni Bhatnagar ${ }^{1}$

To cite: 0'Toole TE, Amraotkar AA, DeFilippis AP, et al. Protocol to assess the efficacy of carnosine supplementation in mitigating the adverse cardiovascular responses to particulate matter (PM) exposure: the Nucleophilic Defense Against PM Toxicity (NEAT) trial. BMJ Open 2020;10:e039118. doi:10.1136/ bmjopen-2020-039118

- Prepublication history for this paper is available online. To view these files, please visit the journal online (http://dx.doi. org/10.1136/bmjopen-2020039118).

Received 06 April 2020 Revised 10 November 2020 Accepted 05 December 2020

Check for updates

(c) Author(s) (or their employer(s)) 2020. Re-use permitted under CC BY-NC. No commercial re-use. See rights and permissions. Published by BMJ.

For numbered affiliations see end of article.

Correspondence to Dr Timothy E. O'Toole; teotoo01@louisville.edu

\section{ABSTRACT}

Introduction Exposure to airborne particulate matter $(\mathrm{PM})$ is associated with cardiovascular disease. These outcomes are believed to originate from pulmonary oxidative stress and the systemic delivery of oxidised biomolecules (eg, aldehydes) generated in the lungs. Carnosine is an endogenous di-peptide ( $\beta$-alanine-Lhistidine) which promotes physiological homeostasis in part by conjugating to and neutralising toxic aldehydes. We hypothesise that an increase of endogenous carnosine by dietary supplementation would mitigate the adverse cardiovascular outcomes associated with PM exposure in humans.

Methods and analysis To test this, we designed the Nucleophilic Defense Against PM Toxicity trial. This trial will enroll 240 participants over 2 years and determine if carnosine supplementation mitigates the adverse effects of PM inhalation. The participants will have low levels of endogenous carnosine to facilitate identification of supplementation-specific outcomes. At enrollment, we will measure several indices of inflammation, preclinical cardiovascular disease and physical function. Participants will be randomly allocated to carnosine or placebo groups and instructed to take their oral supplement for 12 weeks with two return clinical visits and repeated assessments during times of peak PM exposure (June-September) in Louisville, Kentucky, USA. Statistical modelling approaches will be used to assess the efficacy of carnosine supplementation in mitigating adverse outcomes. Ethics and dissemination This study protocol has been approved by the Institutional Review Board at the University of Louisville. Results from this study will be disseminated at scientific conferences and in peerreviewed publications.

Trial registration: NCT03314987; Pre-results

\section{INTRODUCTION}

Extensive epidemiological data show that exposure to particulate matter (PM) air
Strengths and limitations of this study

Selection of a study cohort with inherently low levels of carnosine, thereby facilitating identification of any supplementation-dependent effects.

- Use of diverse endpoints to assess vascular function, physical function and biomarkers of cardiovascular disease.

- Will assess the feasibility of using carnosine to mitigate the effects of particulate matter inhalation.

- Lack of personal exposure monitoring.

- Potential introduction of some bias in cohort selection.

pollution is associated with adverse health outcomes and elevated risk of mortality, especially cardiopulmonary. ${ }^{1-3}$ The World Health Organization (WHO) estimates that exposure to air pollution is linked to 6.5 million deaths (approximately $12 \%$ of total deaths) per year worldwide and that $92 \%$ of the world's population lives in areas where the levels of fine $\mathrm{PM}_{25}$ exceed WHO recommended annual mean concentration limit of $10 \mu \mathrm{g} / \mathrm{m}^{3}$. Thus, identifying effective means to mitigate air pollution-induced pathological outcomes is a priority research area with high scientific and social significance.

While PM exposure contributes to a variety of pulmonary and cognitive disorders ${ }^{45}$ most of the excessive morbidity and mortality associated with PM air pollution is attributable to cardiovascular disease (CVD).$^{6-8}$ Indeed, previous studies have shown that acute and chronic exposures to PM are associated with CVD risk factors such as hypertension ${ }^{910}$ and insulin resistance, ${ }^{11-13}$ thereby contributing to 
atherogenesis, thrombosis and the incidence of myocardial infarction, stroke and sudden cardiac death. ${ }^{14-16}$ Our previous human studies have shown that exposure to PM decreases the levels of circulating angiogenic cells (CACs) and that these changes are accompanied by an increase in levels of circulating endothelial microparticles, immune cells and anti-angiogenic cytokines. ${ }^{17}{ }^{18}$ Related findings in mice are consistent with the idea that exposure to PM induces biomarkers of preclinical CVD. ${ }^{11} 1920$ In addition to lung pathologies, neurocognitive disorders, and CVD, physical limitations are also associated with air pollution exposure, ultimately leading to decreased functional performance, especially in the ageing population. ${ }^{21-24}$

Oxidative stress and inflammation are implicated as causative agents in PM-induced vascular toxicity. Exposure to air pollution has been found to be associated with an increase in several indices of oxidative stress such as urinary isoprostanes and blood myeloperoxidase, ${ }^{25}$ oxidised low-density lipoprotein, ${ }^{26}$ malondialdehyde ${ }^{27}$ and markers of oxidative DNA damage ${ }^{28}{ }^{29}$ Likewise there is evidence that PM exposure increases levels of inflammatory markers such as $\mathrm{C}$ reactive protein (CRP) and interleukin-6 (IL-6) ${ }^{30}$ Despite these associative findings, definitive evidence linking PM-induced inflammation and oxidative stress to CVD is lacking and no effective individual-level interventions are currently available to prevent the adverse cardiovascular effects of PM. Prior attempts to mitigate oxidative stress and air pollutioninduced pathology in humans have been limited to small interventional studies with antioxidant vitamins and omega-3 fatty acids. Although several studies show that supplementation with vitamins $\mathrm{C}, \mathrm{E}$ or $\beta$-carotene can protect against the adverse effects of ozone on lung function, ${ }^{31}$ small interventional studies to assess the effects of omega-3 fatty acids on cardiovascular outcomes have yielded uncertain results; with reported benefits on heart rate variability but not on other vascular parameters. ${ }^{18} 32$ In contrast, administration of N-acetyl-cysteine and ascorbate were found to be associated with an increase, rather than a decrease, in vasoconstriction in individuals exposed to high levels of diesel exhaust. ${ }^{33}$ Other interventional studies have reported marginal effects or no significant effects at all. ${ }^{18}$

We have recently found that dietary supplementation with carnosine, an endogenous di-peptide ( $\beta$-alanyl-Lhistidine) found at high levels in the skeletal muscle, brain and heart mitigates the adverse effects of PM in mice. ${ }^{34}$ Carnosine may mediate these effects by binding to and neutralising unsaturated aldehydes such as acrolein $^{35}$ and 4-hydroxy-trans-2-nonenal, ${ }^{36}$ which are major products of lipid peroxidation and important 'toxic second messengers' of PM-induced reactive oxygen species. Among its other biological activities, carnosine acts as a zwitterion to buffer intracellular $\mathrm{pH}$, reduces the formation of advance glycation end products, and has immunomodulatory effects. ${ }^{37-40}$ Hence, because of these activities and our data demonstrating its therapeutic efficacy in a mouse preclinical

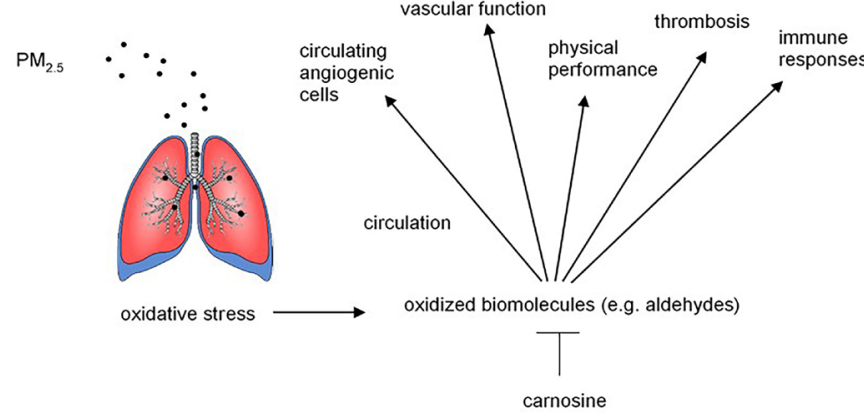

Figure 1 Study rationale. Inhalation of $\mathrm{PM}_{2 \cdot 5}$ induces pulmonary oxidative stress and promotes the generation of oxidised biomolecules. These toxic intermediates are systemically distributed and adversely impact vascular, immune and physical function. By neutralising these biomolecules, carnosine my limit $\mathrm{PM}_{2.5}$-induced pathology. $\mathrm{PM}$, particulate matter.

model, treatment with carnosine represents a viable option for attenuating the oxidative and inflammatory effects of PM exposure in humans (figure 1). This report outlines the Nucleophilic Defense Against PM Toxicity (NEAT) trial. In this randomised, longitudinal clinical study, a human cohort will take a daily, oral supplement of carnosine or placebo during the peak months of air pollution exposure in Louisville, and we will examine vascular function, physical function and biomarkers of CVD risk throughout the treatment duration.

\section{METHODS AND ANALYSIS}

\section{Enrolment criteria and pre-screening}

Participants for the NEAT trial will be selected from the larger Louisville Healthy Heart Study (LHHS) and from de novo recruitment in the Louisville, Kentucky, USA area. Detailed descriptions of the LHHS and demographic characterisations of this cohort have been previously published. ${ }^{41-43}$ To identify participants who might qualify, we will first examine the distribution of previously measured levels of urinary carnosine and carnosine conjugates (figure 2). We will then invite 600 participants in the lower third of the normal distribution, with the expectation of recruiting 240 participants with appropriate demographic characteristics for the NEAT study. The participants will be between 22 and 65 years of age and can be of either gender and of any race or ethnicity. We will exclude individuals with carnosine levels in the upper two-thirds of the population, and those with active treatment for alcohol and drug abuse, or those using immunosuppressant agents or any other medical condition that might compromise the successful completion of the study. Participants will be prescreened, and we will exclude those with conditions known to effect peripheral blood cell counts and bone marrow function such as malignancies, organ transplant, renal replacement therapy, type 1 diabetes, untreated thyroid disease, 


\begin{tabular}{|l|l|l|l|l|l|l|l|l|}
\hline Jan & Feb & Mar & Apr & May & Jun & Jul & Aug & Sep \\
\hline identify potential candidates & & & & & & \\
\hline & $\begin{array}{l}\text { Visit \#1: consent; clinical } \\
\text { screening; candidate selection }\end{array}$ & & & & & \\
\hline & & & & \multicolumn{3}{|l|}{ supplement intervention (12 weeks per participant) } \\
\hline & & & $\begin{array}{l}\text { Visit \#2: baseline } \\
\text { assessment; } \\
\text { initiation of } \\
\text { supplement }\end{array}$ & & & \\
\hline & & & \multicolumn{3}{|l|}{$\begin{array}{l}\text { Visit \# 3: follow-up-1 at 6 } \\
\text { weeks }\end{array}$} & \\
\hline & & & & \multicolumn{3}{|l|}{ Visit \# 4: follow-2 at 12 weeks } \\
\hline
\end{tabular}

Figure 2 NEAT study timeline. Illustrated is the anticipated monthly timeline and study procedures for 2021. The study will continue in 2022 using a similar time frame. NEAT, Nucleophilic Defense Against PM Toxicity.

anaemia, acute infections, HIV infection, hepatitis and unhealed wounds. Participants on hormone replacement therapy or medications affecting bone marrow function or peripheral blood cell counts will also be excluded as will those unwilling or unable to provide informed consent, pregnant or lactating women, prisoners and other vulnerable populations. Eligible and consenting participants will be given a unique trial number which will remain with them throughout the study.

\section{Sample size justification}

The statistical power of the study is estimated based on changes in levels of circulating angiogenic cells (CACs), which will be used as the primary end point of the study. Levels of these cells in humans are impacted by acute changes in PM levels. ${ }^{17}$ Since there are multiple correlated CAC measures, we carefully differentiate between primary and secondary measures based on our previously published results. ${ }^{174142}$ Primarily, we will test changes in levels of CAC-3, CAC-7 and CAC-8 from visit 2 (baseline) to visit 3 (6-week follow-up) between carnosine supplementation and placebo groups, and therefore, we will use adjusted alpha $=0.017(=0.05 / 3)$. Also, we will use a one-sided rather than a two-sided test because compared with placebo, carnosine is unlikely to have significant harmful effects on primary outcome measures. To reduce the effect of heterogeneity, we will compare differences between control and the intervention groups. We plan to enrol $\mathrm{n} 1=120$ and $\mathrm{n} 2=120$. At alpha $=0.017$ and power $=80 \%$, we will be able to detect $0.38 \mathrm{SD}(\mathrm{SD})$ units. When using a longitudinal model approach, ${ }^{44}{ }^{45}$ we will have more power to detect the same effect size, provided consecutive outcome measurements are positively correlated. Based on our experience, we expect an $80 \%$ compliance with reduced sample size of $n 1=100$ and $n 2=100$ and detectable effect size of $0.42 \mathrm{SD}$, which is still a moderate effect size. ${ }^{46}$ However, we will perform both perprotocol (PP) and intention-to-treat (ITT) analysis.
Non-compliance in the carnosine group can be estimated by measurement of urinary conjugates and those individuals will be excluded in the PP analysis but included in the ITT approach. Our sample size for most secondary measurements will have $80 \%$ power, even with $30 \%$ drop-out or non-evaluable participants.

\section{Supplements}

Carnosine is a naturally occurring peptide that is commercially available as a non-prescription-requiring dietary supplement. Carnosine has been previously used as a supplement in placebo-controlled clinical trials at daily doses in the range of $2-4 \mathrm{~g}$ per day. ${ }^{47-50}$ These doses been shown to be safe and efficacious in humans. ${ }^{47} 50$ Thus, participants in our study will receive a daily dose of $2 \mathrm{~g}$ carnosine. The placebo will consist of cornstarch and will match the composition routinely used in clinical interventional studies. Both carnosine and placebo will be encapsulated in identical capsules with a code that is blinded to all but the study physician, data and safety monitoring board (DSMB) and statisticians. The capsules will contain $0.5 \mathrm{~g}$ of material and thus the participants will be required to take four capsules daily for a total of $2 \mathrm{~g}$ of carnosine or cornstarch.

\section{Study plan}

The study will be conducted over two consecutive years with 120 participants each year. The timeline of the study for the first year is shown in figure 2. A list of activities for each study visit is detailed in table 1. After initial screening and selection for inclusion in the study (visit 1), participants will return to the clinic beginning May 1 (visit 2) for baseline assessment. This will involve completion of a questionnaire, collection of demographic information (age, race, gender, socioeconomic status, detailed medical history, medication, alcohol use), and a brief physical exam (height, weight, waist circumference, blood pressure). We will also collect blood, urine, and assess vascular function by measuring arterial stiffness. Finally, we will assess physical performance by using a 2 
Table 1 Study visit procedures

\begin{tabular}{|c|c|c|c|c|c|}
\hline Study activity & Visit \# 1 & Visit \# 2 & Visit \# 3 & Visit \# 4 & 4-12 months safety check \\
\hline Informed consent & $\mathrm{x}$ & & & & \\
\hline Contact and demographics & $\mathrm{x}$ & $\mathrm{x}$ & $\mathrm{x}$ & $\mathrm{x}$ & \\
\hline Medical history and medications & & $\mathrm{x}$ & $\mathrm{x}$ & $\mathrm{x}$ & $x$ \\
\hline Physical examination & & $\mathrm{x}$ & $\mathrm{x}$ & $x$ & \\
\hline Blood samples & $x$ & $\mathrm{x}$ & $\mathrm{x}$ & $\mathrm{x}$ & \\
\hline Urine sample & $\mathrm{x}$ & $\mathrm{x}$ & $\mathrm{x}$ & $\mathrm{x}$ & \\
\hline Arterial stiffness examination & & $\mathrm{x}$ & $\mathrm{x}$ & $\mathrm{x}$ & \\
\hline Physical Performance Assessment & & $\mathrm{x}$ & $\mathrm{x}$ & $\mathrm{x}$ & \\
\hline Questionnaire (sleep, diet, environmental exposures) & & $x$ & $x$ & $x$ & \\
\hline Supplement distribution & & $\mathrm{x}$ & $\mathrm{x}$ & & \\
\hline Adverse events check & & & $\mathrm{X}$ & $\mathrm{X}$ & $\mathrm{X}$ \\
\hline
\end{tabular}

minute step test as an indicator of cardiovascular endurance, the hand grip test as an indicator of upper extremity muscle strength and the calf raise test as an indicator of lower extremity strength. At this time, the participants will also be randomly selected to receive carnosine or placebo supplements. Randomisation will be achieved using a computer-generated scheme in randomly permutated blocks of 6 within eight strata (eg, two age groups, sex, 2 ethnicity groups). Participants and personnel who are involved in outcome measurements will be blinded to group allocation. The participants will be instructed to take their tablets, two in the morning and two in the evening and will continue to take their supplement for the subsequent 12 weeks, until their final clinical visit (visit 4). The carnosine dose will be $0.5 \mathrm{~g}$ per tablet, for a total daily dose of $2 \mathrm{~g}$. This dose is identical to that used in similar clinical trials ${ }^{47} 51$ and is in the range which has demonstrated efficacy in the treatment of diabetic nephropathy. ${ }^{52}$ The placebo will consist of cornstarch. The participants will then return for two more clinical visits (visit 3, visit 4) approximately 6 weeks and 12 weeks after initiation of their carnosine or placebo supplement. These visits will occur between 1 June and 30 September during times of peak PM levels in the metropolitan Louisville area. At these times, we will check for any demographic changes, incidence of adverse outcomes, collect blood and urine, and make assessments of vascular function and physical performance. After visit 4, the participants will cease taking their supplement and be excused from the study, save for a follow-up call 4-12 months later to inquire about any adverse events. The second study year will proceed in an identical manner with a new set of 120 participants.

\section{Collected tissues and clinical measures}

At visits 2-4 (baseline and two follow ups), we will collect blood and urine to measure biomarkers and indices of vascular disease. We will also assess vascular function and physical performance at these time points. A summary of collections and clinical measures are listed in table 2 and detailed below.

\section{Air pollution levels}

Ambient PM levels will be obtained by calculating the daily average of all regional US Environmental Protection Agency (EPA)-validated monitoring stations in the Louisville region that report daily PM levels. These values will be obtained for the prior 24 hours period on the day the study participants have their clinical visits. We will also collect values for the 7 days preceding a clinical visit. Variations in PM between monitors in this area is limited and pollution levels remain rather uniform over large distances.

\section{Carnosine and carnosine conjugate measurements}

Levels of carnosine and its propanol and propanal conjugates will be measured in urine samples using previously described methods. ${ }^{53}$ Carnosine will also be quantified in red blood cells obtained from a heparinised blood collection tube using a mass spectroscopy method and normalised to total protein. ${ }^{54}$

\section{Cellular measurements}

Our prior human studies indicated that exposure to PM induces quantitative changes in discrete peripheral blood cell types and increases the plasma levels of endothelialderived microparticles. ${ }^{17} 18$ Thus, to assess the impact of carnosine or placebo treatments, we will quantify: (1) CACs of 15 phenotypically distinct types; (2) circulating levels of 6 immune cell types; (3) circulating microparticles of 7 distinct phenotypes and (4) levels of platelet aggregates. Measurement of these endpoints is amenable to flow cytometric-based assays on limited amounts of collected blood obtained from the citrate and CPT collection tubes as previously described.$^{1841}$ A phenotypic description of the cell, microparticle and platelet aggregate populations measured is listed in table 3 . The interrelationships between these CACs have been previously defined. ${ }^{184355}$ 
Table 2 Collected tissues and clinical measures

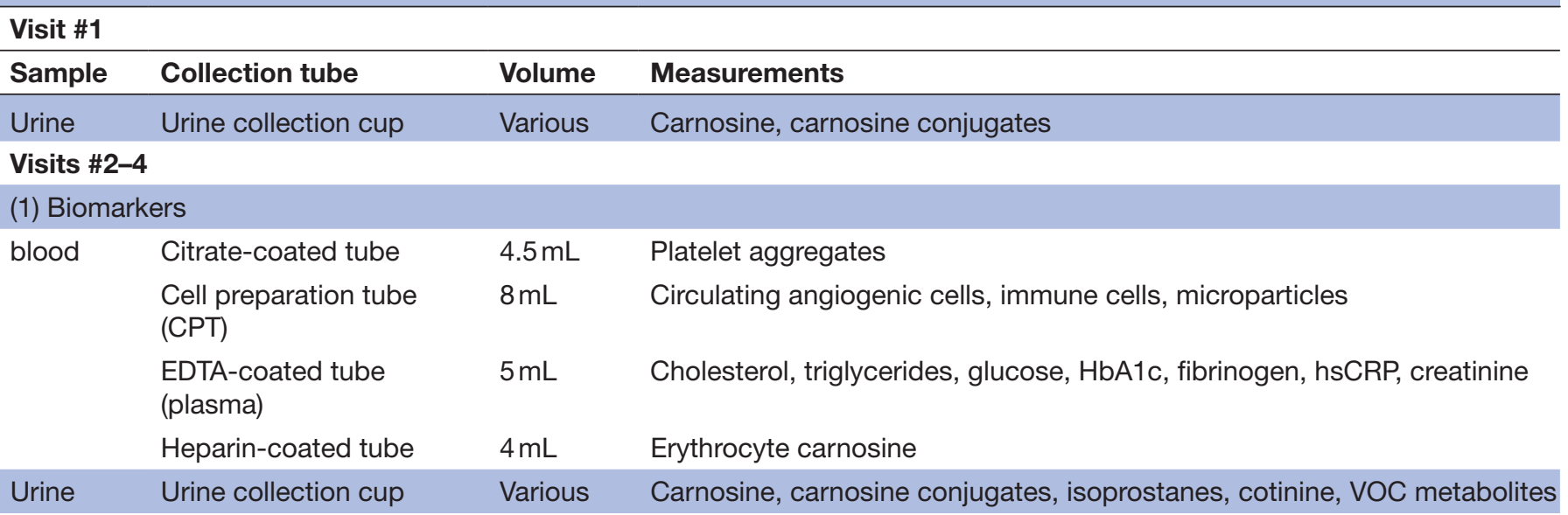

(2) Vascular function

Arterial stiffness

(3) Physical performance

Handgrip, step test, calf raise

VOC, volatile organic compound.

\section{Plasma biomarkers}

Using plasma isolated from an ethylenediamine tetraacetic acid (EDTA) blood collection tube, we will measure a series of soluble biomarkers (table 2), indicative of inflammatory responses and subclinical vascular disease. This will be accomplished by specific ELISAs or through use of an clinical chemistry analyser (Ace Axcel).

\section{Urinary metabolites}

Collected urine samples will be processed and used to measure metabolites of volatile organic compounds (VOCs) (table 4) by previously described mass spectroscopy methods. ${ }^{567}$ Cotinine will be measured using a gas chromatography/mass spectroscopy (GC/MS) method and levels normalised to levels of creatinine, ${ }^{58}$ while isoprostanes will be measured by the Vanderbilt University Eicosanoid Core Laboratory. ${ }^{59}$

\section{Vascular function measurements}

To assess vascular function, we will measure arterial stiffness as determined by pulse wave analysis (PWA). PWA has been established as a reliable tool to predict cardiovascular morbidity and mortality in a variety of adult populations including older adults, patients with end-stage renal disease, diabetes and hypertension. ${ }^{60}$ A pulse wave velocity is calculated by dividing the distance a pressure wave travels by the transit time. We will perform these measurements (applanation tonometry) by recording pressure waveforms at blood vessels in the wrist while looking at the heartbeat using a SphygmoCor instrument (New South Wales, Australia).

\section{Physical performance measurements}

We will assess physical performance using three tests. The first is the handgrip strength test, which assesses upper extremity strength and is reported to be a reliable indicator of a variety of impaired cardiopulmonary conditions. ${ }^{6162}$ Recent studies have reported a negative association between grip strength and air pollution exposure. ${ }^{6364}$ The handgrip strength static test will be assessed as described ${ }^{65}$ using a Jamar Technologies Plus +Digital Hand Dynamometer (JLW Instruments). Participants will be seated in an upright position with their shoulder adducted and elbow flexed at $90^{\circ}$, with the forearm allowed to rest lightly on the arm of the chair or on the subject's thigh. For each subject, a maximal voluntary contraction will be determined as the highest of three initial contractions (INITIAL MAX) ${ }^{66}$ After a 1 min rest period participants will be instructed to squeeze the dynamometer in a static contraction at a level of $50 \%$ of their maximal voluntary contraction for as long as possible, and the duration recorded (DURATION). ${ }^{67}$ The level of static contraction will be monitored by the assessor who provides verbal feedback to ensure that a level of $50 \%$ maximal voluntary contraction is maintained. Participants will then perform an additional post-fatigue maximal contraction within $10 \mathrm{~s}$ of completion of the $50 \%$ maximal static contraction (FINAL MAX). Handgrip testing will be performed on both the dominant and non-dominant hands for each subject. In addition to (INITIAL MAX), (FINAL MAX) and (DURATION), additional calculated indices will be: (1) work performed (WORK=DURATIONx 50\% INITIAL MAX); and (2) Strength Decrement Index (SDI=100x (INITIAL MAX+FINAL MAX)/INITIAL MAX). 


\begin{tabular}{|c|c|}
\hline CACs & Phenotype \\
\hline CAC-1 & $\mathrm{CD} 31^{+} / \mathrm{CD} 34^{+} / \mathrm{CD} 45^{\mathrm{dim}}$ \\
\hline CAC-2 & $\mathrm{CD} 45^{+} / \mathrm{CD} 31^{+} / \mathrm{CD} 34^{+}$ \\
\hline CAC-3 & $\mathrm{CD} 1^{+} / \mathrm{CD} 34^{+} / \mathrm{CD} 133^{+} / \mathrm{CD} 45^{\mathrm{dim}}$ \\
\hline CAC-4 & $\mathrm{CD} 133^{+} / \mathrm{CD} 31^{+} / \mathrm{CD} 34^{+} / \mathrm{CD} 45^{+}$ \\
\hline CAC-5 & $\mathrm{CD}_{133^{+}} / \mathrm{CD} 31^{+}$ \\
\hline CAC-6 & $\mathrm{CD} 1^{+} / \mathrm{CD} 34^{+}$ \\
\hline CAC-7 & $\mathrm{CD} 1^{+} / \mathrm{CD} 34^{+} / \mathrm{CD} 133^{-} / \mathrm{CD} 45^{\mathrm{dim}}$ \\
\hline CAC-8 & $\mathrm{CD} 45^{+} / \mathrm{CD} 31^{+} / \mathrm{CD} 34^{+} / \mathrm{CD} 133^{-}$ \\
\hline CAC-9 & $\mathrm{CD}_{4} 4^{+}$ \\
\hline CAC-10 & $\mathrm{CD}_{3} 1^{+}$ \\
\hline CAC-11 & $\mathrm{CD}_{133^{+}}$ \\
\hline CAC-12 & $\mathrm{CD}_{4} 5^{+}$ \\
\hline CAC-13 & $\mathrm{CD} 4^{+} / \mathrm{CD} 133^{+}$ \\
\hline CAC-14 & $\mathrm{CD}_{133^{+}} / \mathrm{CD} 34^{+} / \mathrm{CD} 45^{+}$ \\
\hline CAC-15 & $\mathrm{CD} 34^{+} / \mathrm{CD} 133^{+} / \mathrm{CD} 45^{\mathrm{dim}}$ \\
\hline
\end{tabular}

Immune cells

\begin{tabular}{ll} 
Monocytes & CD14 \\
NK cells & CD16 \\
\hline NK T cells & $\mathrm{CD}^{+} 6^{+} \mathrm{CD}^{+}$ \\
CD4 T cells & $\mathrm{CD3}^{+} / \mathrm{CD}^{+}$ \\
CD8 T cells & $\mathrm{CD}^{+} / \mathrm{CD}^{+}$ \\
B cells & $\mathrm{CD} 19$ \\
\hline
\end{tabular}

\section{Microparticles}

\begin{tabular}{ll} 
Platelet & Annexin $\mathrm{V}^{+} / \mathrm{CD} 41^{+}$ \\
CAC & Annexin $\mathrm{V}^{+} / \mathrm{CD} 34^{+} / \mathrm{CD} 31^{+}$ \\
\hline Endothelial & Annexin $\mathrm{V}^{+} / \mathrm{CD} 41^{-} / \mathrm{CD} 31^{+}$ \\
\hline Activated endothelial & Annexin $\mathrm{V}^{+} / \mathrm{CD}^{+}$ \\
\hline Lung & Annexin $\mathrm{V}^{+} / \mathrm{CD} 143^{+}$ \\
\hline $\begin{array}{l}\text { Lung endothelial } \\
\text { Lung activated } \\
\text { endothelial }\end{array}$ & Annexin $\mathrm{V}^{+} / \mathrm{CD} 143^{+} / \mathrm{CD} 41^{-} / \mathrm{CD} 31^{+}$ \\
\hline
\end{tabular}

\section{Platelet aggregates}

\begin{tabular}{|c|c|}
\hline Leucocytes & $\mathrm{CD} 41^{+}, \mathrm{CD} 45^{+}$ \\
\hline Granulocytes & $\begin{array}{l}\text { Size gated subpopulation of } \\
\mathrm{CD} 41^{+}, \mathrm{CD} 45^{+}\end{array}$ \\
\hline Monocytes & $\begin{array}{l}\text { Size gated subpopulation of } \\
\mathrm{CD} 41^{+}, \mathrm{CD} 45^{+}\end{array}$ \\
\hline Lymphocytes & $\begin{array}{l}\text { Size gated subpopulation of } \\
\text { CD } 41^{+}, C D 45^{+}\end{array}$ \\
\hline
\end{tabular}

CAC, circulating angiogenic cell.

The second test of physical performance will be the 2 min step test (2MST). The 2MST is an alternative to the 6 min walk test for assessment of aerobic endurance and can be predictive of morbidity and mobility in older adults or those with CVD. ${ }^{68}$ Higher scores on the 2MST indicate increased functionality, quality of life and decreased incidence of chronic health problems. ${ }^{69}$ To perform the test, participants are asked to stand next to a wall and march in place with the intent of raising the knees to a marked target on the wall mid-way, representing a height between the lateral condyle and anterior superior iliac spine of the participant. The test administrator counts the number of times the right knee reaches the marked target over a $2 \mathrm{~min}$ period. If an individual cannot march for the full $2 \mathrm{~min}$, they are permitted to take a standing or seated rest break and resume within the $2 \mathrm{~min}^{70}$

The third physical capacity test will be the bilateral calf-raise test. ${ }^{71}$ This is a muscle strength and endurance test that has been used to evaluate the functional performance of older adults and those with CVD ${ }^{71-74}$ Initially, participants will stand barefoot and in a bipedal position facing a wall and will be supported with their dominant hand on the wall and elbow in semiflexion to maintain balance. The participant will perform plantar flexion with maximum range for all repetitions. The first flexion is executed using the full range of motion, up to the point of support on the metatarsophalangeal joints. At full flexion, the examiner marks the maximum height reached by the participant's head with an adjustable height instrument. This will ensure that the individual performs plantar flexion using full range of motion in every repetition. A verbal command will be given to start the test and the participant will perform the maximum number of plantar flexions possible, as fast as possible until the point of voluntary fatigue. Measurements include the number of plantar flexions performed during the bilateral calf-raise, total time in seconds and repetition rate (repetitions per second). These outcomes can then be normalised for differences in participant physical characteristics such as body mass index, height, weight and age.

\section{Study visits}

There will be a total of four study visits. Visit 1 will be used to screen participants for endogenous carnosine levels. Visit 2 will be used for baseline assessment and randomisation of supplement. Visit 3 will be the first follow-up at 6 weeks from baseline. Visit 4 will be the second follow-up at 12 weeks from baseline.

\section{Primary endpoints}

The primary endpoint of this study is a change in the levels of CAC-3, CAC-7 and CAC-8 from visit 2 (baseline) to visit 3 (6-week follow-up) between carnosine supplementation and placebo groups. Primary outcomes will be declared significant for alpha $<0.017$.

\section{Secondary endpoints}

There are four secondary endpoints of this study: (1) changes in levels of CAC-3, CAC-7 and CAC-8 from visit 2 (baseline) to visit 4 (12-week follow-up); (2) changes in arterial stiffness from visit 2 (baseline) to visit 3 (6-week follow-up); changes in endothelial microparticles from visit 2 (baseline) to visit 3 (6-week follow-up) and (4) changes in platelet monocyte aggregates from visit 2 
Table 4 Measured VOC metabolites

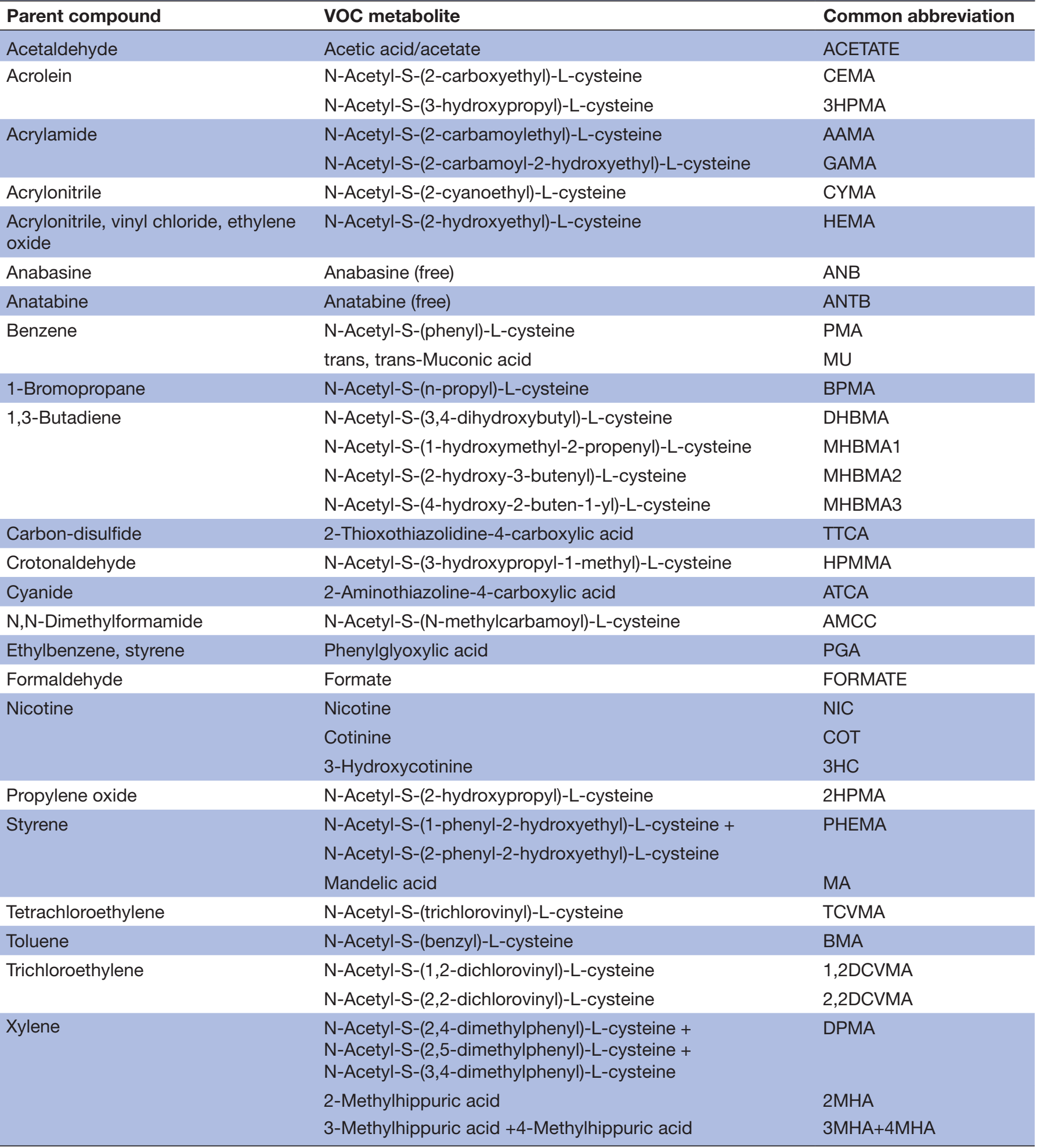

VOC, volatile organic compound.

(baseline) to visit 3 (6-week follow-up). All comparisons will be between carnosine supplementation and placebo groups. There will not be any adjustments for secondary outcome measures, and these will be declared significant at alpha $<0.05$.

\section{Data and safety monitoring board}

The DSMB will be comprised of four experts responsible for reviewing clinical trial data on an ongoing basis to ensure the safety of study participants and validity and integrity of the data. Members will have no vested interest 
in the specific outcomes of dietary supplementation. The DSMB will review evidence of any adverse events and interim outcomes to recommend whether the trial should be continued, altered or terminated. The DSMB will have access to 'unmasked' data during the trial, meaning that DSMB members will know which participants are in which supplement group.

\section{Data analysis}

Continuous variables will be presented by summary statistics (such as mean, median, SE, range, 95\% CI, correlations) and the categorical variables by frequency distributions (frequency counts, percentages and $95 \% \mathrm{CI}$ ). For discrete variables with fewer than $5 \%$ expected cell frequency, Fisher's exact method will be used and will be noted; otherwise, $95 \%$ CI will be constructed using the normal approximation. The effect of intervention and PM exposure on the outcomes (table 2) will be estimated using mixed effects models. ${ }^{445}{ }^{45}$ We will use interaction variables to detect whether the associations between PM and outcomes are significantly different between the plus and minus carnosine groups. We will perform a formal mediation analysis, which allows for interactions to determine the degree to which carnosine levels impact the effect of PM on our outcomes. Plots of subject-specific differences over pollution concentrations along with regression plots will be generated. In initial analyses, we will use PM concentrations 24 hours prior to the blood draws. However, other models that use PM concentrations 1-7 days prior to the blood draw will also be developed. The per cent change (and 95\% CIs) for measured analytes per $10 \mu \mathrm{g} / \mathrm{m}^{3}$ increase in PM relative to its mean value will be calculated. This approach comprehensively evaluates all measured analytes, allows for direct comparisons and evaluation of the strength of the statistical associations, and mitigates concerns regarding multiple testing and selective reporting. Since the main outcome variables are CAC-3/5/7, we will split the subjects into two groups based on the median values of levels of these CACs and then identify the confounders and covariates affecting CAC levels. An overarching GLM model, along with group indicator for intervention and significant covariates associating with these CACs be included in the analyses. We will also use propensity score adjustments to reduce the number of variables, as previously discussed. ${ }^{76}$ Taking into account the explained variability due to multiple covariates, the post hoc power analyses will be performed. ${ }^{77}$ The results will be declared significant at alpha $=0.017$ for primary outcome variables and 0.05 for the others, using the SAS statistical software version 9.4. ${ }^{75} 78$ We will adjust $p$ values obtained in the subject analyses or due to multiple outcomes. ${ }^{79}$ In case of high dimensional data, we use false discovery rate procedures to address the issues of multiple comparisons. ${ }^{80} 81$

Imputation techniques for missing data in clinical studies require different approaches. The missing data mechanism describes the probability of a response being observed or missing. We usually observe three reasons for missing data: (1) missing completely at random (MCAR), (2) missing at random (MAR) and (3) not MAR (NMAR). Under MCAR, the missing data process does not depend on the observed outcomes nor the observed covariates. MAR implies that the missing data process only depends on the observed covariates and the outcome measure. However, under NMAR the missing data mechanism depends on the values of the missing covariates or the outcome measure. When the data are MAR, then some 'ad hoc' methods for imputing the data, such as mean value of the available observations, may provide biased estimates. The methods based on likelihood or generalised estimating equations approaches provide valid inferences. As missing data can hinder downstream analyses, there are a variety of ways in which to deal with missing values in large data sets. ${ }^{82-84}$ Missing observation(s) likely to be below the limit of detection (LOD) will be replaced by LOD/sqrt. Beyond LOD imputations, if any variable is missing more than half the time, that variable will not be included in the multiple regression or generalised linear model analyses. In repeat measure analysis for a genuinely missing variable(s) (ex. a biological sample at a given time point is missing or contaminated), we will employ a mixed model approach that uses the remaining time point observations. We will compare results from imputed and not-imputed data.

\section{Analytical populations}

Three distinct analytical populations have been defined for this study: safety, ITT and PP. These populations are a subset of all the participants enrolled in the study.

\section{Safety population}

This subset will consist of all study participants who have received at least one dose of study supplement (carnosine or placebo) and have completed at least one subsequent follow-up visit during which an adverse event check was performed (visit 3 or 4). All safety related analysis, including those done by the DSMB, will be performed on the safety population.

\section{ITT population}

This population will consist of all participants who received any study supplement (carnosine or placebo). This subset will follow the assumption that all participants should be analysed as per the group that they were originally randomly assigned to. This population will be used for assessing the effectiveness of carnosine supplementation for the primary endpoint. This analysis population will be considered primary.

\section{Per-protocol population}

This population will consist of participants who complied will all components of the study and strictly adhered to the study protocol. All participants of this subset will have successfully completed the entire study from visit 1 (screening) through Visit 4 (12-week follow-up), without having committed any protocol violations or deviations that dismisses them from the study. This population 
will also be used to assess the effectiveness of carnosine supplementation for the primary endpoint. This analysis population will be considered secondary.

As per Consolidated Standards of Reporting Trials guidelines for parallel group randomised control trial (carnosine vs placebo), we will perform analysis for both, ITT and PP population, with ITT being conducted as the primary analysis population. ${ }^{85}$

\section{Strengths and limitations}

This study will test the hypothesis that carnosine protects against the adverse effects of PM exposure in humans. The rationale for this hypothesis is supported by findings from our previous animal studies. ${ }^{34}$ Positive results would have wide implications for the use of carnosine in preventing PM-induced cardiovascular injury in vulnerable populations. A major strength of our study is its design. Participants selected for the study will be those with inherently low levels of carnosine, as we expect any salubrious effects of supplementation will be most apparent in such a population and that those with high levels of carnosine at baseline are unlikely to benefit from additional supplementation. Moreover, each subject will serve as their own control with baseline, pre-exposure measurements, and two return visits during times of peak exposure. This work is also significant because we will undertake extensive measures of exposure (PM, VOCs, microparticles, isoprostanes), immune function (circulating immune cell populations, highly sensitive CRP), endothelial function (arterial stiffness, CACs), thrombogenicity (platelet aggregates) and indicators of CVD risk (cholesterol, triglycerides, glucose, hemoglobin A1C $(\mathrm{HbAlc}))$. Only by assessing this diverse and extensive set of outcomes can we gain any insight into the extent and efficacy of carnosine-mediated protection.

While participants in our study will be those with endogenously low levels of carnosine, this selection criteria may also introduce a bias to our study. Specifically, carnosine is generally more abundant in males than females ${ }^{86}$ and in a younger population than an older population. ${ }^{8788} \mathrm{In}$ addition, some racially distinct polymorphisms have been identified in carnosine-degrading enzymes, which may also influence endogenous levels. ${ }^{89-93}$ While this selection bias can be minimised by subgroup analysis, it nonetheless will not invalidate one of our study hypotheses, that the effects of carnosine supplementation will be more apparent in those with inherently low levels. Another weakness of this study is that we will not conduct personal monitoring of PM exposure. An estimate of ambient PM levels will be obtained by calculating the daily average of all regional EPA-validated monitoring stations in the Louisville region that report daily PM levels. Variations in PM between monitors is limited and remains rather uniform over large distances. However, we cannot account for personal occupational or residential exposures to levels of PM which may deviate from that in the larger metropolitan Louisville area. A final weakness is that it may be difficult to assess compliance. While participants will be given reminders to take their daily supplements, and we will request pill counts at follow-up visits, there is no assurance that the supplements have been consumed. In addition, for those taking the placebo, skewed outcomes may result from those who have high levels of meat consumption, as carnosine is highly abundant in animal muscle. ${ }^{86}$ Nevertheless, some insight into compliance can be obtained from the measurement of carnosine and its conjugates in collected urine samples.

\section{Patient and public involvement}

The participants or the general public will not be involved in the design, execution, analysis or reporting of this study.

\section{ETHICS AND DISSEMINATION}

All participants provide written consent and no studyrelated procedures will be completed until consent is obtained. Study procedures pose minimal risk. Carnosine is already used as a dietary supplement and is commercially available. The requested supplement of $2 \mathrm{~g}$ per day is within accepted levels and has proven therapeutic efficacy. ${ }^{94}$ The placebo will consist of corn starch.

Individuals taking the supplements $(n=240)$ will be recruited from the Louisville, Kentucky area and will have less than the median (0.36) carnosine level in all measured participants $(n>1100)$. Gender ${ }^{86}$ and age $-{ }^{88}$ specific differences in endogenous expression levels may introduce some demographic bias in our study cohort. Similarly, genetic ${ }^{95}$ or ethnic-specific ${ }^{96}$ differences in carnosine-metabolising enzymes may impact endogenous levels and likewise bias the makeup of our cohort. Nevertheless, any potential impact of carnosine supplementation can most clearly be observed in a population with inherently lower levels. Participant information will be de-identified for analysis and reported in aggregate to protect privacy.

Completion of these studies will establish whether a practical intervention (carnosine supplementation) can limit the deleterious effects of PM exposure. Data generated from this study may form the basis for larger clinical studies similarly investigating the therapeutic efficacy of carnosine in response to PM or other inhaled pollutants (eg, cigarette smoke, aerosolised metals) that also induce oxidative stress and/or the generation of toxic byproducts (eg, aldehydes).

Results from this study will be disseminated to the public in the form of peer-reviewed publications. After publication, resources generated with funding for this study will be made available to interested and qualified investigators on written request. The study will also provide relevant protocols of published data, on request, assuming prior publication. Participants will be provided with a summary of the results as they become available. Finally, press releases of relevant findings will inform the general population. 


\section{Author affiliations}

${ }^{1}$ Division of Environmental Medicine, Christina Lee Brown Envirome Institute, University of Louisville, Louisville, Kentucky, USA

${ }^{2}$ Division of Cardiovascular Medicine, University of Louisville, Louisville, Kentucky, USA

${ }^{3}$ Department of Medicine, Vanderbilt University, Nashville, TN, USA

${ }^{4}$ Department of Biostatistics and Bioinfomatics, University of Louisville, Louisville, Kentucky, USA

${ }^{5}$ Department of Chemistry, University of Louisville, Louisville, KY, USA

${ }^{6}$ Department of Physical Therapy, Bellarmine University, Louisville, Kentucky, USA

${ }^{7}$ Department of Economics, Brigham Young University, Provo, Utah, USA

Correction notice This article has been corrected since it first published. The provenance and peer review statement has been included.

Contributors TEO: study design, study funding, endpoint measurements, manuscript preparation; AAA: study design, recruitment, study visits, vascular function, manuscript preparation; APD: study design, clinical oversight; SNR: study design, statistical analysis: RJK: study design, recruitment, study visits, vascular function; SPB: study design; PL: endpoint measurements; CEC: study design, endpoint measurements; GLP: study design, endpoint measurements; CJW: study design, endpoint measurements; CAP: study design, study funding, statistical analysis, manuscript preparation; $A B$ : study design, study funding, manuscript preparation.

Funding This work is supported by a grant from the National Institutes of Health (R01ES019217)

Competing interests None declared.

Patient and public involvement Patients and/or the public were not involved in the design, or conduct, or reporting, or dissemination plans of this research.

Patient consent for publication Not required.

Provenance and peer review Not commissioned; externally peer reviewed.

Open access This is an open access article distributed in accordance with the Creative Commons Attribution Non Commercial (CC BY-NC 4.0) license, which permits others to distribute, remix, adapt, build upon this work non-commercially, and license their derivative works on different terms, provided the original work is properly cited, appropriate credit is given, any changes made indicated, and the use is non-commercial. See: http://creativecommons.org/licenses/by-nc/4.0/.

ORCID iD

Timothy E. 0'Toole http://orcid.org/0000-0003-1773-1523

\section{REFERENCES}

1 Chen $\mathrm{H}$, Goldberg MS, Villeneuve PJ. A systematic review of the relation between long-term exposure to ambient air pollution and chronic diseases. Rev Environ Health 2008;23:243-97.

2 Heal MR, Kumar P, Harrison RM. Particles, air quality, policy and health. Chem Soc Rev 2012;41:6606-30.

3 Dockery DW, Pope CA, Xu X, et al. An association between air pollution and mortality in six U.S. cities. $N$ Engl $J$ Med 1993;329:1753-9.

4 Calderón-Garcidueñas L, Calderón-Garcidueñas A, Torres-Jardón $\mathrm{R}$, et al. Air pollution and your brain: what do you need to know right now. Prim Health Care Res Dev 2015;16:329-45.

5 Li R, Zhou R, Zhang J. Function of PM2.5 in the pathogenesis of lung cancer and chronic airway inflammatory diseases. Oncol Lett 2018;15:7506-14.

6 Bhatnagar A. Cardiovascular pathophysiology of environmental pollutants. Am J Physiol Heart Circ Physiol 2004;286:H479-85.

7 Bhatnagar A. Environmental cardiology: studying mechanistic links between pollution and heart disease. Circ Res 2006;99:692-705.

8 Pope CA, Dockery DW. Health effects of fine particulate air pollution: lines that connect. J Air Waste Manage Assoc 2006;56:709-42.

9 Krishnan RM, Adar SD, Szpiro AA, et al. Vascular responses to longand short-term exposure to fine particulate matter: MESA air (multiethnic study of atherosclerosis and air pollution). J Am Coll Cardiol 2012;60:2158-66.

10 Chen H, Burnett RT, Kwong JC, et al. Spatial association between ambient fine particulate matter and incident hypertension. Circulation 2014;129:562-9.

11 Haberzettl P, O'Toole TE, Bhatnagar A, et al. Exposure to fine particulate air pollution causes vascular insulin resistance by inducing pulmonary oxidative stress. Environ Health Perspect 2016;124:1830-9.

12 Sun Q, Yue P, Deiuliis JA, et al. Ambient air pollution exaggerates adipose inflammation and insulin resistance in a mouse model of diet-induced obesity. Circulation 2009;119:538-46.

$13 \mathrm{Xu}$ X, Liu C, Xu Z, et al. Long-Term exposure to ambient fine particulate pollution induces insulin resistance and mitochondrial alteration in adipose tissue. Toxicol Sci 2011;124:88-98.

14 Pope CA, Muhlestein JB, May HT, et al. Ischemic heart disease events triggered by short-term exposure to fine particulate air pollution. Circulation 2006;114:2443-8.

15 Künzli N, Jerrett M, Mack WJ, et al. Ambient air pollution and atherosclerosis in Los Angeles. Environ Health Perspect 2005;113:201-6.

16 Pope CA, Burnett RT, Thurston GD, et al. Cardiovascular mortality and long-term exposure to particulate air pollution: epidemiological evidence of general pathophysiological pathways of disease. Circulation 2004;109:71-7.

17 O'Toole TE, Hellmann J, Wheat L, et al. Episodic exposure to fine particulate air pollution decreases circulating levels of endothelial progenitor cells. Circ Res 2010;107:200-3.

18 Pope CA, Bhatnagar A, McCracken JP, et al. Exposure to fine particulate air pollution is associated with endothelial injury and systemic inflammation. Circ Res 2016;119:1204-14.

19 Haberzettl P, Conklin DJ, Abplanalp WT, et al. Inhalation of fine particulate matter impairs endothelial progenitor cell function via pulmonary oxidative stress. Arterioscler Thromb Vasc Biol 2018;38:131-42.

20 Haberzettl P, Lee J, Duggineni D, et al. Exposure to ambient air fine particulate matter prevents VEGF-induced mobilization of endothelial progenitor cells from the bone marrow. Environ Health Perspect 2012;120:848-56.

21 de Zwart F, Brunekreef B, Timmermans E, et al. Air pollution and performance-based physical functioning in Dutch older adults. Environ Health Perspect 2018;126:017009.

22 García-Esquinas E, Rodríguez-Artalejo F, Pollutants E. Environmental pollutants, limitations in physical functioning, and frailty in older adults. Curr Environ Health Rep 2017;4:12-20.

23 Lin $\mathrm{H}$, Guo $\mathrm{Y}$, Zheng $\mathrm{Y}$, et al. Exposure to ambient $\mathrm{PM}_{2.5}$ associated with overall and domain-specific disability among adults in six lowand middle-income countries. Environ Int 2017:104:69-75.

24 Weuve J, Kaufman JD, Szpiro AA, et al. Exposure to traffic-related air pollution in relation to progression in physical disability among older adults. Environ Health Perspect 2016;124:1000-8.

25 Li W, Wilker EH, Dorans KS, et al. Short-Term exposure to air pollution and biomarkers of oxidative stress: the Framingham heart study. J Am Heart Assoc 2016;5.

26 Brucker N, Moro AM, Charão MF, et al. Biomarkers of occupational exposure to air pollution, inflammation and oxidative damage in TAX drivers. Sci Total Environ 2013;463-464:884-93.

27 Sørensen M, Daneshvar B, Hansen M, et al. Personal PM2.5 exposure and markers of oxidative stress in blood. Environ Health Perspect 2003;111:161-6.

28 Ren C, Fang S, Wright RO, et al. Urinary 8-hydroxy-2'deoxyguanosine as a biomarker of oxidative DNA damage induced by ambient pollution in the normative aging study. Occup Environ Med 2011;68:562-9.

29 Rossner Jr. P, Rossnerova A, Sram RJ. Oxidative stress and chromosomal aberrations in an environmentally exposed population. Mutat Res 2011;707:34-41.

30 Li W, Dorans KS, Wilker EH, et al. Short-Term exposure to ambient air pollution and biomarkers of systemic inflammation: the Framingham heart study. Arterioscler Thromb Vasc Biol 2017;37:1793-800.

31 Romieu I, Castro-Giner F, Kunzli N, et al. Air pollution, oxidative stress and dietary supplementation: a review. Eur Respir J 2008;31:179-97.

32 Tong H, Rappold AG, Diaz-Sanchez D, et al. Omega-3 fatty acid supplementation appears to attenuate particulate air pollutioninduced cardiac effects and lipid changes in healthy middle-aged adults. Environ Health Perspect 2012;120:952-7.

33 Sack CS, Jansen KL, Cosselman KE, et al. Pretreatment with antioxidants augments the acute arterial vasoconstriction caused by diesel exhaust inhalation. Am J Respir Crit Care Med 2016;193:1000-7.

34 Abplanalp W, Haberzettl P, Bhatnagar A, et al. Carnosine supplementation mitigates the deleterious effects of particulate matter exposure in mice. J Am Heart Assoc 2019;8:e013041.

35 Baba SP, Hoetker JD, Merchant M, et al. Role of aldose reductase in the metabolism and detoxification of carnosine-acrolein conjugates. J Biol Chem 2013;288:28163-79. 
36 Orioli M, Aldini G, Benfatto MC, et al. Hne Michael adducts to histidine and histidine-containing peptides as biomarkers of lipidderived carbonyl stress in urines: LC-MS/MS profiling in Zucker obese rats. Anal Chem 2007;79:9174-84

37 Caruso G, Fresta CG, Martinez-Becerra F, et al. Carnosine modulates nitric oxide in stimulated murine RAW 264.7 macrophages. Mol Cell Biochem 2017:431:197-210.

38 Rashid I, van Reyk DM, Davies MJ. Carnosine and its constituents inhibit glycation of low-density lipoproteins that promotes foam cell formation in vitro. FEBS Lett 2007;581:1067-70.

39 Tan KML, Candlish JK. Carnosine and anserine as modulators of neutrophil function. Clin Lab Haematol 1998;20:239-44.

40 Tanaka K-I, Sugizaki T, Kanda Y, et al. Preventive effects of carnosine on lipopolysaccharide-induced lung injury. Sci Rep 2017;7:42813.

41 DeJarnett N, Conklin DJ, Riggs DW, et al. Acrolein exposure is associated with increased cardiovascular disease risk. J Am Heart Assoc 2014;3.

42 DeJarnett N, Yeager R, Conklin DJ, et al. Residential Proximity to Major Roadways Is Associated With Increased Levels of AC133 + Circulating Angiogenic Cells. Arterioscler Thromb Vasc Biol 2015;35:2468-77.

43 Zafar N, Krishnasamy SS, Shah J, et al. Circulating angiogenic stem cells in type 2 diabetes are associated with glycemic control and endothelial dysfunction. PLOS One 2018;13:e0205851.

44 Diggle PJ, Heagerty PJ, Liang KY, et al. Analysis of longitudinal data. 2nd Edn. New York: Oxford University Press, 2002.

45 Rai SN, Hudson MM, McCammon E, et al. Implementing an intervention to improve bone mineral density in survivors of childhood acute lymphoblastic leukemia: BONEII, a prospective placebo-controlled double-blind randomized interventional longitudinal study design. Contemp Clin Trials 2008;29:711-9.

46 Cohen J. Statistical power analysis for the behavioral sciences. 2nd Edn. New Jersy: Lawrence Erlbaum Associates Publishers, 1988.

47 de Courten B, Jakubova M, de Courten MPJ, et al. Effects of carnosine supplementation on glucose metabolism: pilot clinical trial. Obesity 2016;24:1027-34.

48 Derave W, Özdemir MS, Harris RC, et al. $\beta$-Alanine supplementation augments muscle carnosine content and attenuates fatigue during repeated isokinetic contraction bouts in trained sprinters. J Appl Physiol 2007;103:1736-43.

49 Harris RC, Tallon MJ, Dunnett M, et al. The absorption of orally supplied $\beta$-alanine and its effect on muscle carnosine synthesis in human vastus lateralis. Amino Acids 2006;30:279-89.

50 Regazzoni L, de Courten B, Garzon D, et al. A carnosine intervention study in overweight human volunteers: bioavailability and reactive carbonyl species sequestering effect. Sci Rep 2016;6:27224

51 Baye E, Ukropec J, de Courten M, et al. Carnosine supplementation improves serum resistin concentrations in overweight or obese otherwise healthy adults: a pilot randomized trial. Nutrients 2018;10:1258.

52 Elbarbary NS, Ismail EAR, El-Naggar AR, et al. The effect of 12 weeks carnosine supplementation on renal functional integrity and oxidative stress in pediatric patients with diabetic nephropathy: a randomized placebo-controlled trial. Pediatr Diabetes 2018;19:470477.

53 Hoetker D, Chung W, Zhang D, et al. Exercise alters and $\beta$-alanine combined with exercise augments histidyl dipeptide levels and scavenges lipid peroxidation products in human skeletal muscle. J Appl Physiol 2018. doi:10.1152/japplphysiol.00007.2018. [Epub ahead of print: 18 Oct 2018].

54 Chaleckis R, Murakami I, Takada J, et al. Individual variability in human blood metabolites identifies age-related differences. Proc Natl Acad Sci U S A 2016;113:4252-9.

55 Yeager R, Riggs DW, DeJarnett N, et al. Association between residential Greenness and cardiovascular disease risk. J Am Heart Assoc 2018;7:e009117.

56 Barski OA, Xie Z, Baba SP, et al. Dietary carnosine prevents early atherosclerotic lesion formation in apolipoprotein E-Null mice. Arterioscler Thromb Vasc Biol 2013;33:1162-70.

57 Lorkiewicz P, Riggs DW, Keith RJ, et al. Comparison of urinary biomarkers of exposure in humans using electronic cigarettes, Combustible cigarettes, and smokeless tobacco. Nicotine Tob Res 2019;21:1228-38.

58 Man CN, Gam L-H, Ismail S, et al. Simple, rapid and sensitive assay method for simultaneous quantification of urinary nicotine and cotinine using gas chromatography-mass spectrometry. $J$ Chromatogr B Analyt Technol Biomed Life Sci 2006;844:322-7.

59 Milne GL, Sanchez SC, Musiek ES, et al. Quantification of F2isoprostanes as a biomarker of oxidative stress. Nat Protoc 2007;2:221-6.
60 Mitchell GF, Guo C-Y, Benjamin EJ, et al. Cross-Sectional correlates of increased aortic stiffness in the community: the Framingham heart study. Circulation 2007;115:2628-36.

61 Kovarik M, Joskova V, Patkova A, et al. Hand grip endurance test relates to clinical state and prognosis in COPD patients better than 6-minute walk test distance. Int J Chron Obstruct Pulmon Dis 2017:12:3429-35.

62 Artero EG, Lee D-chul, Lavie CJ, et al. Effects of muscular strength on cardiovascular risk factors and prognosis. J Cardiopulm Rehabil Prev 2012;32:351-8.

63 Guo YF, Ruan Y, Lin HL, et al. [Association between low handgrip strength and air pollution among people aged 50 years and over] Zhonghua Liu Xing Bing Xue Za Zhi 2019;40:1240-4.

64 Lin H, Guo Y, Ruan Z, et al. Association of indoor and outdoor air pollution with Hand-Grip strength among adults in six lowand middle-income countries. J Gerontol A Biol Sci Med Sci 2020;75:340-7.

65 Reuter SE, Massy-Westropp N, Evans AM. Reliability and validity of indices of hand-grip strength and endurance. Aust Occup Ther $J$ 2011;58:82-7.

66 Lagerström C, Nordgren B. On the reliability and usefulness of methods for grip strength measurement. Scand J Rehabil Med 1998;30:113-9.

67 Trossman PB, Li P-W. The effect of the duration of Intertrial rest periods on isometric grip strength performance in young adults. The Occupational Therapy Journal of Research 1989;9:362-78.

68 Wegrzynowska-Teodorczyk K, Mozdzanowska D, Josiak K, et al. Could the two-minute step test be an alternative to the six-minute walk test for patients with systolic heart failure? Eur J Prev Cardiol 2016;23:1307-13.

69 Rikli RE, Jones CJ. Functional fitness normative scores for community-residing older adults, ages 60-94. J Aging Phys Act 1999;7:162-81.

70 Rikli RE, Jones CJ. Development and validation of a functional fitness test for Community-Residing older adults. J Aging Phys Act 1999;7:129-61.

71 Monteiro DP, Britto RR, Fregonezi GAdeF, et al. Reference values for the bilateral heel-rise test. Braz J Phys Ther 2017;21:344-9.

72 Cider A, Carlsson S, Arvidsson C, et al. Reliability of clinical muscular endurance tests in patients with chronic heart failure. Eur $J$ Cardiovasc Nurs 2006;5:122-6.

73 McDermott MM, Hoff F, Ferrucci L, et al. Lower extremity ischemia, calf skeletal muscle characteristics, and functional impairment in peripheral arterial disease. J Am Geriatr Soc 2007;55:400-6.

74 van Uden CJT, van der Vleuten CJM, Kooloos JGM, et al. Gait and calf muscle endurance in patients with chronic venous insufficiency. Clin Rehabil 2005;19:339-44.

75 Little RC, Miliken GA, Stroup WW, et al. SAS $®$ for mixed models. 2nd Edn. Cary, N.C: SAS Institute Inc, 2006

76 SNW R, Srivastava X.; Craycroft DK, et al. Review: propensity score methods with application to the help clinic clinical study. Open Access Medical Statistics 2018;8:11-23.

77 Hsieh FY, Bloch DA, Larsen MD. A simple method of sample size calculation for linear and logistic regression. Stat Med 1998;17:1623-34.

78 Dmitrienko A, Molenberghs G, Chuang-Stein C, et al. Analysis of clinical trials using $S A S \otimes$ : a practical guide. Cary, N.C.: SAS Institute Inc, 2005

79 Westfall $\mathrm{PH}$, Tobias RD, Wolfinger RD. Multiple comarisons and multiple tests using SAS, 2011.

80 Benjamini $Y$, Hochberg Y. Controlling the false discovery rate: a practical and powerful approach to multiple testing. Journal of the Royal Statistical Society: Series B 1995;57:289-300.

81 Benjamini Y, Krieger AM, Yekutieli D. Adaptive linear step-up procedures that control the false discovery rate. Biometrika 2006;93:491-507.

82 Fong DYT, Rai SN, Lam KSL. Estimating the effect of multiple imputation on incomplete longitudinal data with application to a randomized clinical study. J Biopharm Stat 2013;23:1004-22.

83 Little RJA, Rubin DB. Statistical analysis with missing data. 2nd edn. Wiley, 2002.

84 Shah JS, Rai SN, DeFilippis AP, et al. Distribution based nearest neighbor imputation for truncated high dimensional data with applications to pre-clinical and clinical metabolomics studies. BMC Bioinformatics 2017:18:114.

85 Schulz KF, Altman DG, Moher D, et al. Consort 2010 statement: updated guidelines for reporting parallel group randomised trials. PLOS Med 2010;7:e1000251.

86 Boldyrev AA, Aldini G, Derave W. Physiology and pathophysiology of carnosine. Physiol Rev 2013;93:1803-45. 
87 Johnson P, Hammer JL. Histidine dipeptide levels in ageing and hypertensive rat skeletal and cardiac muscles. Comp Biochem Physiol B 1992;103:981-4.

88 Tallon MJ, Harris RC, Maffulli N, et al. Carnosine, taurine and enzyme activities of human skeletal muscle fibres from elderly subjects with osteoarthritis and young moderately active subjects. Biogerontology 2007;8:129-37.

89 Chakkera HA, Hanson RL, Kobes S, et al. Association of variants in the carnosine peptidase 1 gene (CNDP1) with diabetic nephropathy in American Indians. Mol Genet Metab 2011;103:185-90.

90 Freedman BI, Hicks PJ, Sale MM, et al. A leucine repeat in the carnosinase gene CNDP1 is associated with diabetic end-stage renal disease in European Americans. Nephrol Dial Transplant 2007:22:1131-5.

$91 \mathrm{Kim}$ S, Abboud HE, Pahl MV, et al. Examination of association with candidate genes for diabetic nephropathy in a Mexican American population. CJASN 2010;5:1072-8.
92 Kurashige M, Imamura M, Araki S-I, et al. The influence of a single nucleotide polymorphism within CNDP1 on susceptibility to diabetic nephropathy in Japanese women with type 2 diabetes. PLoS One 2013;8:e54064.

93 Poon PY-K, Szeto C-C, Kwan BC-H, et al. Relationship between carnosinase gene CNDP1 leucine repeat polymorphism and the clinical outcome of Chinese PD patients. Clin Nephrol 2010;74:343-5.

94 Elbarbary NS, Ismail EAR, El-Naggar AR, et al. The effect of 12 weeks carnosine supplementation on renal functional integrity and oxidative stress in pediatric patients with diabetic nephropathy: a randomized placebo-controlled trial. Pediatr Diabetes 2018;19:470-7.

95 Ahluwalia TS, Lindholm E, Groop LC. Common variants in CNDP1 and CNDP2, and risk of nephropathy in type 2 diabetes. Diabetologia 2011;54:2295-302.

96 Mooyaart AL, van Valkengoed IGM, Shaw PKC, et al. Lower frequency of the $5 / 5$ homozygous CNDP1 genotype in South Asian Surinamese. Diabetes Res Clin Pract 2009;85:272-8. 